\title{
Microseismic Monitoring of Hard Rock Mine Slopes
}

\author{
J. Wesseloo Australian Centre for Geomechanics, The University of Western Australia, Australia \\ G.J. Sweby Gold Fields International, Australia
}

\begin{abstract}
Open pit mine slopes are likely to increase in depth in the future. With this comes an increased stress environment and a greater uncertainty regarding the mechanical behaviour of the slopes. Microseismicity detectable in the slope provides a valuable source of information about its mechanical behaviour. Microseismic monitoring has been used at several large natural rock slope, civil and open pit mine slopes with varying degrees of success. In spite of some operational difficulties experienced at different sites, the method shows a lot of promise. The paper gives an overview of microseismic monitoring of rock slopes and discusses the measured seismicity at an open pit mine in Australia relative to the in situ stress state. Fracture initiation at the site occurred at stress levels below the expected rock mass strength and appears to be consistent with both the conceptual model for the development of instability in hard rock slopes suggested by Eberhardt et al. (2004) and Stead et al. (2007), as well as the concepts underlying the cohesion-softeningfriction-hardening constitutive models.
\end{abstract}

\section{Introduction}

In a paper written in 1967 Jennings and Steffen commented on the trends of increasing depth of open pit mines. This trend is still continuing with several rock slopes being mined in excess of $500 \mathrm{~m}$. Some mine slopes have reached slope heights greater than $800 \mathrm{~m}$ and several others are planned to reach these depths in the foreseeable future.

With this increasing depth comes an increasing stress environment and a greater uncertainty regarding the mechanical behaviour of the slopes, which relates to an increased safety and economic risk. Stacey (2007) concluded that conventional approaches for the evaluation of stability of rock slopes in a high stress hard rock environment are of questionable validity as the true processes involved in the development of instability are not accounted for by these methods.

Eberhardt et al. (2004) points out that massive rock slope failure processes are largely driven by the initiation and propagation of brittle tensile fractures driven by extensional strain, which interact with natural preexisting discontinuities to eventually form basal and internal shear planes. They also point out that shear failure only becomes a factor once enough tensile fracture damage was incurred to allow mobilisation.

In an attempt to describe the brittle fracture processes governing slope behaviour, Stead et al. (2007) distinguish three brittle fracture processes.

- The primary brittle fracture is considered to include processes that occur prior to the onset of failure:

- Propagation of failure surfaces through fracture tip growth.

- Coalescence of fractures and failure of intact rock bridges.

- Shearing along discontinuities involving removal of asperities.

- The secondary brittle fracture processes are associated with a transition from the initiation to the transportation stage in a slope failure and involves:

- Development of rear lateral release surface.

- Internal deformation, fracturing and dilation.

- Tertiary brittle fracture processes involving the comminution of the rock mass associated with transport leading up to final debris flow. 
Microseismicity detectable in the slope provides a potentially valuable source of information for all three of the brittle fracture processes mentioned previously and enhance the understanding of stress induced failure mechanisms in rock slopes. With current developments in the modelling of rock masses, microseismic data provides unique opportunities for calibrating and enhancing these models.

This paper provides an overview of microseismic monitoring in hard rock slopes as well as a discussion of the monitored seismicity at an Australian open pit mine.

\section{General overview of microseismicity in rock slopes}

\subsection{Natural rock slopes and civil engineering slopes}

The use of microseismic (MS) monitoring in natural, civil and mine slopes generally appears to be motivated by the need for early warning of developing slope instability. Its use for this purpose is based on the fact that the seismicity generated inside the rock mass will be detected at very small strains and will therefore be detected before surface movement is visible.

Some early references are made to the use of acoustic emission (AE) techniques in slope stability studies (McCauley, 1976; Hardy, 1981; Hardy and Kimble, 1991). Although its use for slope monitoring has been limited, Hardy (1994) mentions an increased use in the 1990s. For these studies the general approach to slope stability monitoring was to plot the count rate verses time curve for each monitoring station. When the count rate reaches an arbitrary level, remedial work and/or precautions are taken (Koerner et al., 1981).

More recent examples of the use of AE/MS monitoring of small slopes are that of Ishida et al. (2001) and Amitrano et al. (2005). The assessment of AE rates was used by Ishida et al. (2001) to monitor an unstable rock mass in a road cutting. Ishida et al. (2001) used the rate of AE emission as a stability indicator and reported a correlation between $\mathrm{AE}$ rate and rate of movement. Amitrano et al. (2005) monitored the seismicity before and up to the failure of a $50 \mathrm{~m}$ high $1000-2000 \mathrm{~m}^{3}$ chalk cliff collapse in the Normandy ocean shore of France. They showed a power-law acceleration of seismicity rate and energy prior to collapse and an increase in the average size of the seismic event towards the time of failure.

Several installations of microseismic systems for the monitoring of large natural slopes are also reported in literature. It appears that the first large rock slope instrumented with microseismic systems was the Turtle Mountain in Alberta, USA. Instrumentation of the Turtle Mountain was motivated by the history of instability and the proximity to towns and infrastructure. The project team expected that events emanating from inside the mountain may be associated with stress relief and that it could be landslide precursors. Microseismic monitoring of Turtle Mountain was first carried out from June to September of 1981 with a single monitoring station. This was followed by the installation of a six-sensor array that recorded data from November 1986 until June 1996, the results of which are discussed by Chen et al. (2004). At this site deep events related to thrust fault movement as well as near surface events attributed to surface fractures were observed. In November 2003 another surface array was installed on the mountain (Stewart et al., 2004).

The Randa rockslide in the Swiss Alps is one of three sites originally instrumented with small trial seismic systems (Eberhardt et al., 2004; Willenberg et al., 2002). During the first month of operation of the experimental sites at Randa, the seismic network recorded several signals which could be attributed to fracturing in the underlying rock mass. For the Randa rockslide, displacement rates of 10 to $20 \mathrm{~mm} / \mathrm{year}$ of 10 million $\mathrm{m}^{3}$ of ground was monitored between 1991 and 2002. To study progressive failure and pre-failure rock mass deformations in massive crystalline rock slopes at the Randa Rockslide Laboratory a microseismic system was deemed essential (Willenberg et al., 2002). An array consisting of 12 triaxial geophones was installed in 2001. A large number of noise events resulted in an exceptionally large volume of data. Poor quality data was obtained in the project volume, which was attributed to the presence of large open fractures deep below the surface, across which passing waves are strongly attenuated (Eberhardt et al., 2004; Willenberg et al., 2002).

Roth and Blirka (2007) mention the monitoring of the unstable Aaknes rock slope in Norway with an eight triaxial geophone array installed in October 2005. The unstable volume is estimated at 40-70 million $\mathrm{m}^{3}$ with a movement rate of between 4 and $15 \mathrm{~cm} /$ year. About 1 to 10 local microseismic events, with good signal quality, occurred per week. Locating the seismic events proved difficult because of the close 
proximity and the difficulty in picking the S-phase arrivals, as well as a heterogeneous rock mass with strong variations of seismic velocities. They observed increased seismic activity during periods with heavy rainfall and snow melt. A correlation between increased activity and climatic variations is also mentioned by Clement et al. (2006) reporting on the installation of an array on part of the Rochers de Valabres slopes in the southern Alps region in France.

Brückl and Mertl $(2006,2007)$ report the microseismic monitoring of deep seated gravitational creep movement of crystalline Alpine rocks at three different sites. Slope deformation rates at these sites varied between $20-40 \mathrm{~mm} /$ year at two of the sites and about $200-600 \mathrm{~mm} /$ year at the other. The recorded moment magnitude for these sites ranged between -2 and 0 . They estimated the seismic fault area to be about a 1000 times smaller than the area of the sliding plane and concluded that most of the internal deformation or sliding occurred a-seismically or with seismic emission below the detection level of their system.

From the literature it appears that the technology in the monitoring of natural and cut slopes for civil excavations is not regarded as having reach maturity, in the sense that it can be used as a routine monitoring method. The studies are often preliminary or experimental in nature and require a great deal of expert interpretation.

From the experience gained from civil excavations and large natural slopes it appears that microseismic monitoring can provide valuable insight into all three of the brittle fracture processes described by Stead et al. (2007) (cf. Section 1).

\subsection{Mining rock slopes}

Although microseismic monitoring has been performed routinely for many in underground mines around the world, its use in open pit mines is fairly recent. This is the result of both hardware limitation and the fact that the potential value of microseismic monitoring for the open pit environment was not appreciated.

The first reference of microseismic activity in open pit mines appears to be that of Deza and Jaén in 1979. They recorded microseismic events by chance during a study of blasting effects outside a limestone quarry and recorded about 50 microseismic events occurring before and after each quarry blast.

Kalgoorlie Consolidated Gold Mines (KCGM) appears to be the first mine to install a seismic system for the purpose of monitoring a slope. A trial array was installed in 1996 which was later extended (Kable, 2005).

Table 1 Open pit mine sites referred to in literature where microseismic monitoring has been performed

\begin{tabular}{lll}
\hline Mine & Country & Reference \\
\hline Cerro de Paco & Peru & Deza and Jaén (1979) \\
Fimiston (Super Pit) & Australia & Hudyma et al. (2003) \\
Navachab & Namibia & Lynch et al. (2005) \\
Sandsloot & South Africa & Lynch et al. (2005) \\
Sunrise Dam & Australia & Lynch and Malovichko (2006) \\
Crosscourse Pit Union Reefs & Australia & Lynch et al. (2005) \\
Mt Keith & Australia & Sweby et al. (2006) \\
Chuquicamata & Chile & Trifu et al. (2008) \\
\hline
\end{tabular}

According to Lynch and Malovichko (2006), microseismic monitoring has been performed at more than 25 open pit slopes. It appears that some of these sites may have had arrays consisting of a limited number of sensors. The experience at only six of these sites is discussed in literature. Table 1 provides a list of published sites experience the authors are aware of. 
Typically only a small section of the slope is monitored and, to date, the seismic systems installed in open pit mines have been limited in both operation time (relative to the mining of the slope) and the monitored volume.

\section{Practical considerations for the use of microseismic monitoring in open pit mine slopes}

Although some of the hardware limitations preventing the use of microseismic monitoring in open pits have been overcome, the effective use of this technology in open pits is still faced with several difficulties.

The first difficulty is that of the rapidly changing environment of open pit mining. Interim slopes are short lived and continuing pit optimisation results in small changes in the planned pit geometry as mining progresses. Access to the slopes is often restricted to areas surrounding the ramps and crests. The seismic system is rigid and may, as a result, be short lived when installed from a location within the pit. Even small design changes in the pit geometry may result in the shortening of the life of the system or impact negatively on the effectiveness of the system. Installing the system from the pit crest is comparatively expensive as this involves specialised drilling of long boreholes. Sites with continued access are often limited to ramps and the pit crest.

Smaller events, compared to that of the underground environment, need to be measured in slopes. As a result, the inter-sensor spacing needs to be closer than that of an underground system in order to measure and reliably locate these events.

Due to the comparatively low stress environment the seismic signals are weak and signal to noise ratio's are low. Our experience at two Australian mines (Mines A and B) showed that more noise than events are triggered, resulting in a large data set having to be manually filtered to remove non-events. For one of these mines only about $1-2 \%$ of the triggered events were retained as real events. This is similar to the experience from the Randa rockslide mentioned by Eberhardt et al. (2004). Koerner et al. (1981) also pointed out that noise discrimination has become a major consideration in acoustic emission monitoring of geotechnical structures.

The weakness of the events also results in events often being difficult to process, resulting in poorer than desired location accuracy. With the weak events and relatively low frequency of events, the accurate location of each recorded event is important. This results in a high processing burden on personnel as the automatic processing is generally not satisfactory with small events.

The difficulty in locating events and the distinction between noise and a weak event is illustrated by Figure 1, showing the result of routine manual processing of data from an open pit mine in Australia. Several alignments of events, as a consequence of event location of noise, are visible.

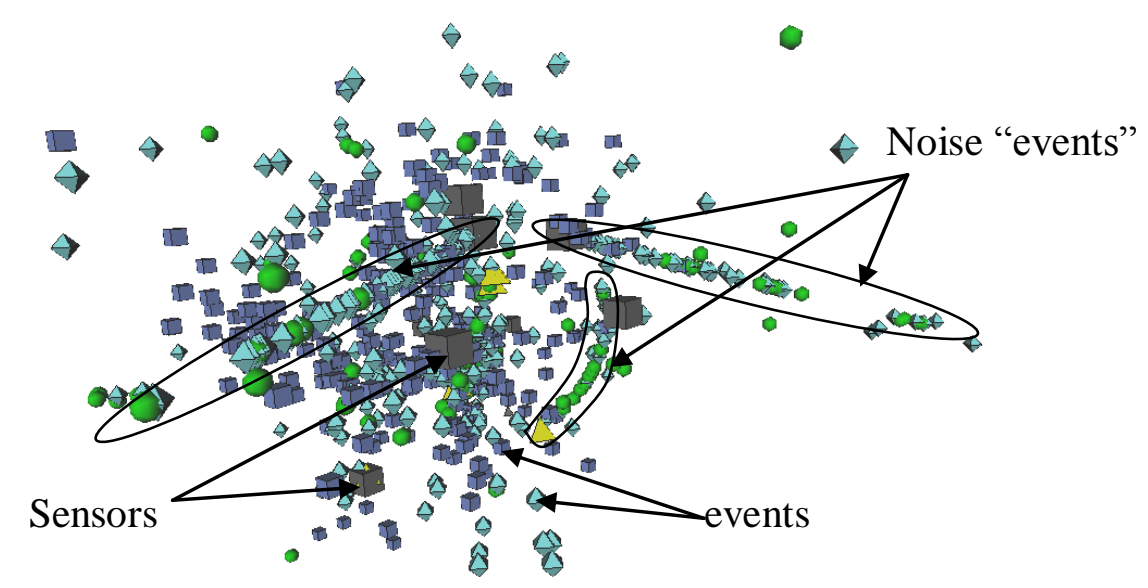

Figure 1 Result of blind processing of data from open pit mine seismic data 
Trifu et al. (2008) mentions that only $20 \%$ of the recorded events at Chuquicamate open pit needed to be manually reprocessed. This experience supports our previous conclusion as the majority of the events recorded at the other sites, falls below the magnitudes recorded at Chuquicamata.

Any excavation alters the stress field and causes redistribution of stresses to take place. In the underground environment the excavations are often relatively small and under confined conditions. The stress changes caused by the excavations are limited in extent and different areas of the mine can often be viewed as independent. In underground environments, generally, the monitored volume is large compared to the influence zones of the excavations. In contrast, the open pit mines exposes very extensive surfaces and the influence zone of the excavations is large compared to the volume of the rock monitored by the seismic systems that have, to date, been installed at open pit mines.

For the primary brittle fracture process in the rock slope under low stress, dilative, load releasing environment, it is expected that the seismicity would be related to the tensional fracturing of rock bridges or, expressed differently, extensional fracturing rather than shear fracturing (Einstein et al., 1983; Lajtai, 1969; Stacey et al., 2003). The generally applied routine methods for assessing the seismic source parameters is based on the assumption of a double-couple shear mechanism, which may not be applicable for most of the events measured in the open pit environment (i.e. primary and part of secondary fracture process). Lynch and Malovichko (2006) mention the failure of the Brune model to describe the seismicity experienced at Navachab mine. This is also the case for the near surface extensional fracturing that occurred in the mine-by tunnel at the Underground Research Laboratory (URL) in Canada (Cai et al., 1998). In the open pit environment, the interpretation of seismological source parameters, other than location, is therefore not clear.

Having pointed out some of the difficulties associated with its implementation in the open pit environment, it is important to realise the value of the technology. With the general increase in the economic depth of open pits it is becoming very important to understand the influence of stress and the processes governing fracturing at low stress, which ultimately govern the behaviour of rock slopes in deep hard rock pits. Towards this end, the microseismic monitoring provides a means for obtaining information that would otherwise be unavailable.

\section{General assessment of the seismicity in open pit mines}

\subsection{Environments for seismicity}

Microseismic monitoring detects the sound energy emitted from brittle fracturing that occurs in the rock mass and can therefore only be used where the damage in the rock mass occurs as a result of cumulative brittle fracturing. However, in a low stress, near surface environment, the limits of where this fracture process will result in recordable seismicity are currently unknown.

Whether or not a rock mass will emit recordable seismicity will ultimately depend on the properties and stress state of the rock mass. Lynch and Malovichko (2006) report recordable seismicity in a rock slope with intact rock UCS of 20 to $50 \mathrm{MPa}$. The seismicity mentioned by Deza and Jaén (1979) occurred at a depth of only $60 \mathrm{~m}$, although the quarry footprint was large (1200 by $750 \mathrm{~m})$. Lynch and Malovichko (2006) reported a slope height of $80 \mathrm{~m}$ to be enough to generate recordable microseismicity. Stacey (2007) reports face bursts occurring at a dimension stone quarry at depths of only a few meters.

At an Australian open pit mine (Mine A) the recorded seismicity occurred at uniaxial stress levels of between 5 and $15 \mathrm{MPa}$. This stress level is about $10 \%$ of the uniaxial strength of the intact rock.

\subsection{Microseismic response to mining}

There appears to be some correlation between the mining activity and the seismic activity. This is illustrated by the experience at several sites. Figure 2 shows a strong correlation between the cumulative number of seismic events and the amount of rock removed at the bottom of the Navachab pit as a function of time (Lynch and Malovichko, 2006).

Hudyma et al. (2003) report an increase in event frequency at the Fimiston pit when blasting occurred in close proximity, while Cowley (1998) (in Kable, 2005) showed that a time decay of seismic events occurs after blasting (Figure 3). 
Although there is little doubt that the transient stress wave from blasting induces some damage to the near surface rock mass, it does not appear to be the main driver of the micro seismicity deeper into the slope, which we attribute to the fracture growth at low stress taking place in the slope as a result of pseudo-static stress change. This conclusion is also supported by Lynch and Malovichko (2006) who observed an increase in the microseismic activity, about two days after a blast at Navachab mine. They also report the rapid decrease in seismicity after removal of the blasted rock at the toe of the slope at another Australian mine.

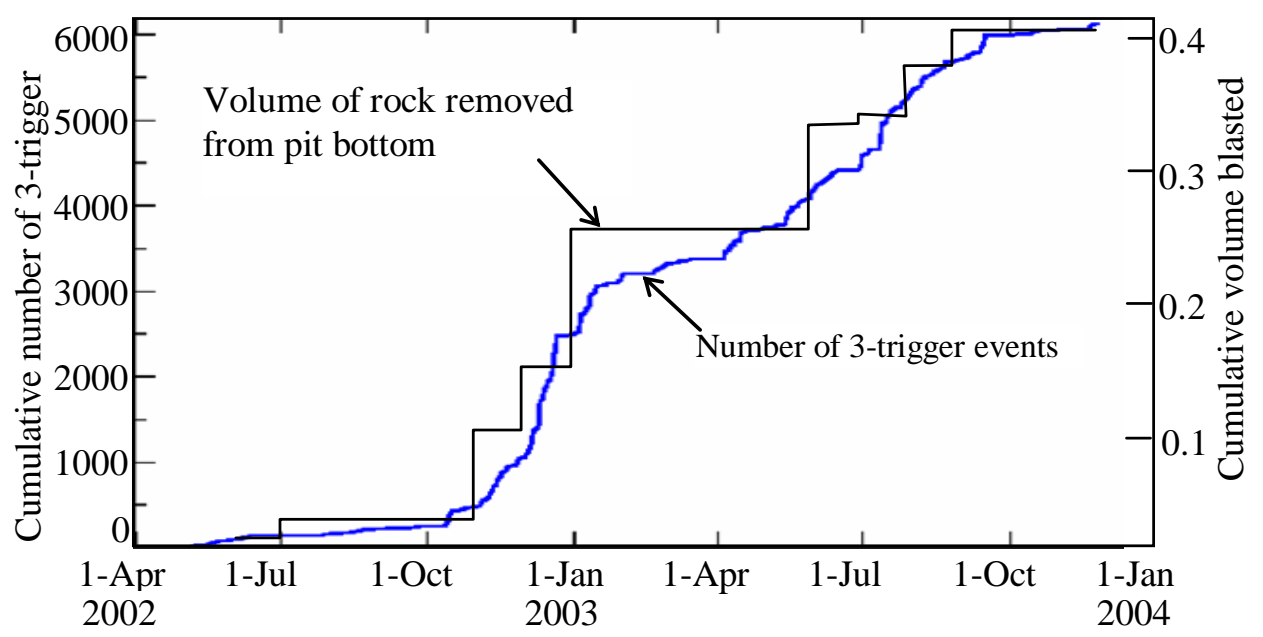

Date

Figure 2 Comparison between seismic activity and mining rate at Navachab mine (modified after Lynch and Malovichko, 2006)

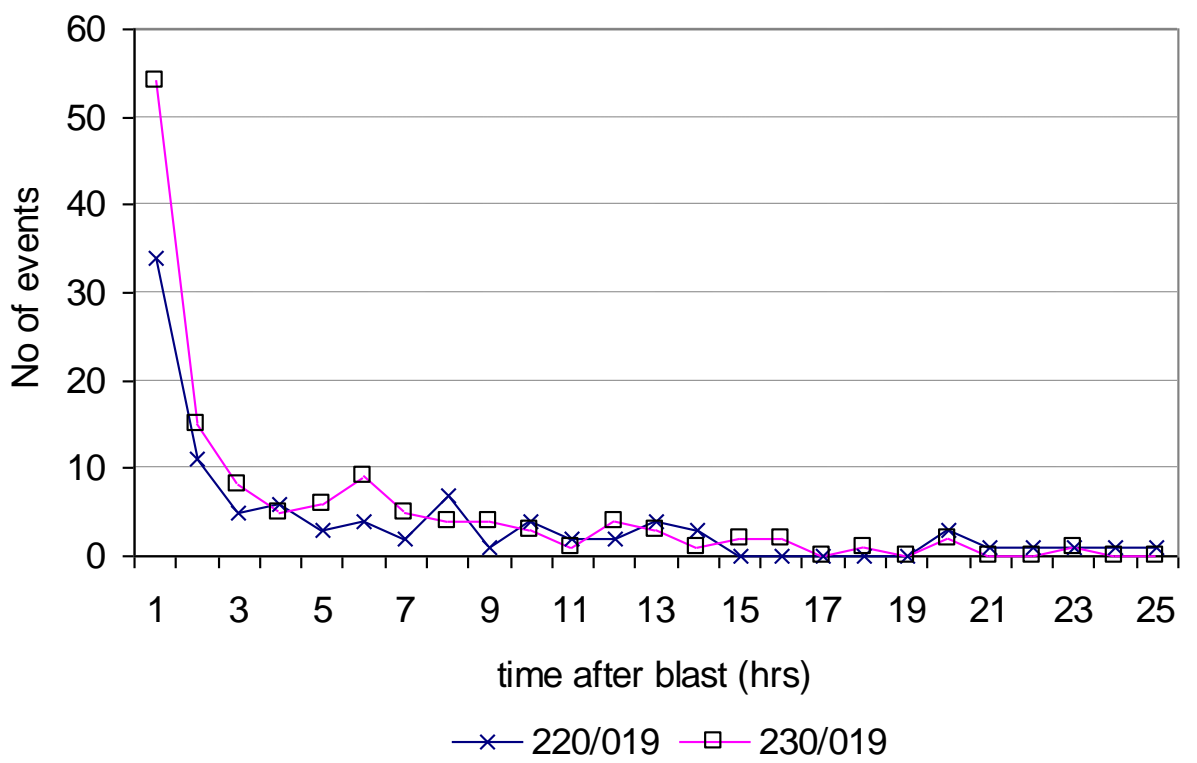

Figure 3 Time decay of seismicity after production blasting (after Cowley, 1998)

\subsection{Event size}

Due to the low stress environment, the energy associated with seismic events in the open pit environment is small $(<20 \mathrm{~J})$ compared to that generally measured in the underground environment $(<3 \cdot 105 \mathrm{~J})$. Figure 4 provides a comparison between the recorded seismicity from different environments.

In terms of the energy associated with the seismicity, there is some overlap between the upper levels of seismic energy release in the open pit environment and the lower levels of the seismicity recorded in 
underground mines. These events are associated with "popping" and "cracking" of the rock around excavations, as the rock reacts to newly imposed stress changes. The lower level of the measured open pit seismicity overlap with the upper levels of seismicity experienced from extensional fracturing at the mine-by tunnel at the URL and is similar to that experienced when sinking the shaft at the same research centre.

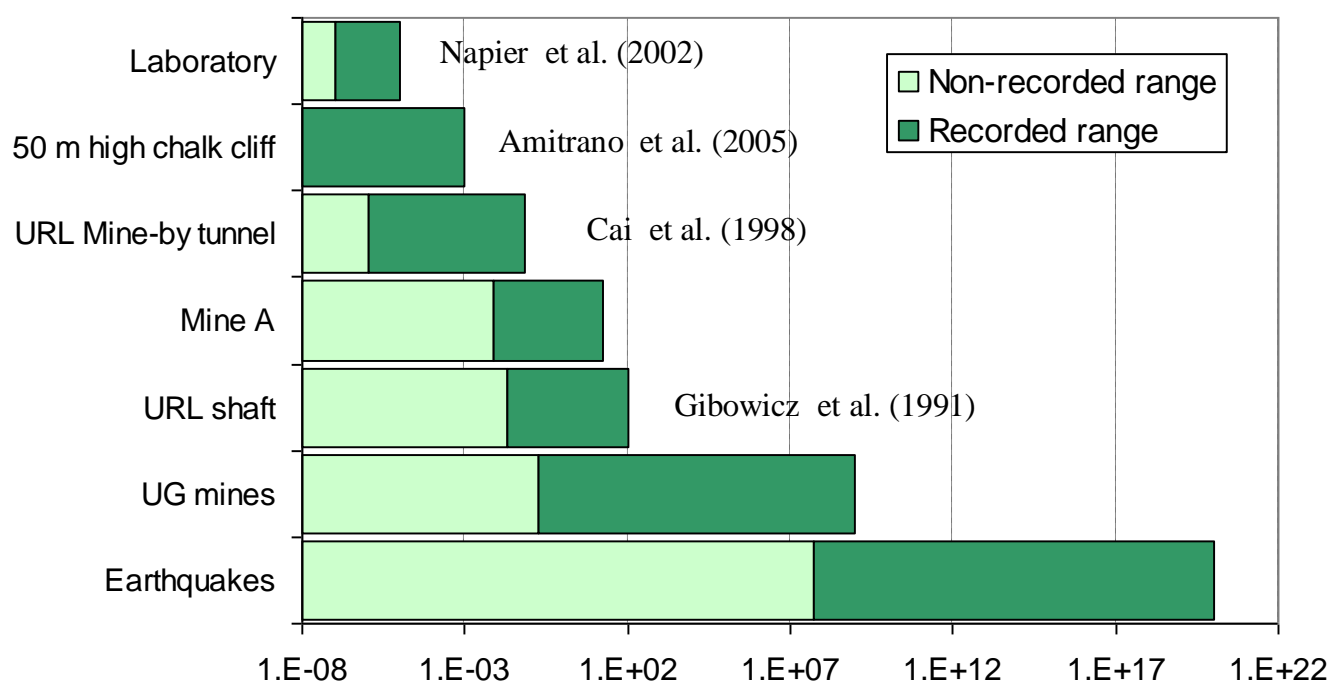

Seismic Energy (J)

\section{Figure 4 Seismic energy related to different areas of seismology}

The recorded moment magnitudes of several open pit sites is summarised in Table 2. Of interest is the similarity of the recorded moment magnitude over several sites with varying conditions, with exception of Chuquicamata which is considerably deeper than any of the other sites mentioned. Trufi et al. (2008) mentioned that a large number of these events occurred below the level of the pit bottom (i.e. $>800 \mathrm{~m}$ depth). For the other sites there appears to be an empirical upper limit of about 0 . This upper limit might be governed by the relatively low stresses causing fracturing and the mode of fracture creation and may be an indication of the similarity of the fracture processes occurring within the different rock masses.

Table 2 Recorded moment magnitude values from rock slopes

\begin{tabular}{llcc}
\hline \multirow{2}{*}{ Site } & Reference & Recorded Magnitudes (Moment Magnitude) \\
& & Min & Max \\
\hline Cerro de Pasco & Deza and Jaén (1979) & -2 & 0 \\
Sandsloot & Lynch et al. (2005) & -2.5 & -0.5 \\
Navachab & Lynch et al. (2005) & -2 & 0 \\
Mine A & & -1.6 & -0.6 \\
Mine C & & -2 & 0 \\
Chuquicamata & Trifu et al. (2008) & -0.7 & 1.4 \\
Large natural rock slopes & Brückl and Mertl (2006) & -2 & 0 \\
\hline
\end{tabular}

Figure 5 shows the frequency-magnitude plot of the local magnitude for the recorded seismicity at Mine A. The expected power-law relationship is shown in Figure 5, the $b$-value is high at about 1.6. It is interesting to note that high $b$-values $(\sim 1.2-1.5)$ in an underground environment are often associated with seismicity 
resulting from fresh fracturing of the rock following stress changes resulting directly from blasting (Legge and Spottiswoode, 1987; Hudyma et al.,1995). The slope of the linear part of the frequency-magnitude plot is dependent on the magnitude scale that is used. For the seismic system used at Mine A, the $b$-value obtained from the local magnitude appears to be similar to that which will be obtained for Richter magnitude.

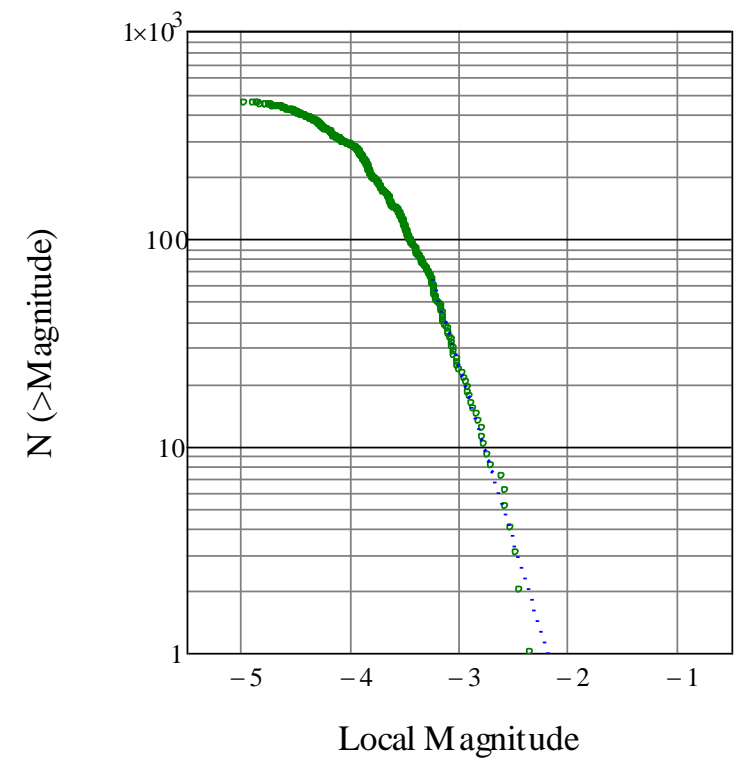

Figure 5 Frequency-magnitude relationship for the data

\subsection{S-wave to $P$-wave energy ratios}

Under low confining stress, shear failure of rock does not occur, as this would require the major stress in the rock to exceed its UCS. Fracturing in this environment occurs as a result of local tensile stresses occurring at fracture tips and in rock bridges as a result of imposed shear stresses (Einstein et al., 1983; Lajtai, 1969).

The ratio of energy associated with the $\mathrm{S}$-wave and $\mathrm{P}$-wave $\left(E_{s} / E_{p}\right)$ is dependent on the focal mechanism at the seismic source and is therefore an important indicator of the type of focal mechanism (Cai et al., 1998). In pure shear the $E_{s}$ is considerably larger than $E_{p}\left(E_{s} / E_{p}>20\right)$. On the other hand, for the tensile model presented by Sato (1978) it is shown that $E_{p}$ and $E_{s}$ are approximately equal. Gibowicz et al. (1991) and Gibowicz and Kijko (1994) suggest that $E_{s} / E_{p}<10$ the source mechanism involves a tensile failure component.

Figure 6 shows the distribution of $E_{s}$ to $E_{p}$ ratio of the recorded data at Mine A. The majority of the data falls below 10 with the average being as low as 2.2. Ten percent of the Mine A data has an $E_{s} / E_{p}$ ratio of less than unity indicating pure tensile behaviour.

This data can be benchmarked against the data obtained from other environments. Figure 6 plots $E_{s}$ to $E_{p}$ for the data from Mine A with that recorded for the extension fracturing resulting in dog-earing in the roof and floor of the Mine-by tunnel at the URL in Canada as well as the data obtained from the sinking of the shaft at the same research institute (Gibowicz et al.,1991; Cai et al., 1998). Application of a shear type source model to the recorded events from the Mine-by tunnel resulted in unrealistically large estimates of source radius (Cai et al., 1998). A tensile source model presented by (Cai et al., 1998), produced estimates of source radius comparable to observations. Both the mean and the variation of the $E_{s} / E_{p}$ ratio is lower for the Mine A data than that from the extensional fracturing at the URL mine-by tunnel.

The distribution of $E_{s} / E_{p}$ ratio from different environments is compared in Table 3 and Figure 7 . It is interesting to note the general increase in the recorded $E_{s} / E_{p}$ ratio with increased confinement as shown in Figure 7. 
From experience with different seismic system, it appears that the calculation of $E_{s} / E_{p}$ ratio is, to some extent, dependent on the seismic system. With exception of the earthquake data, the data compared here were all obtained from the same type of seismic system.

The low values of $E_{s} / E_{p}$ recorded at Mine A strongly indicates that the microseismicity is not dominated by a shear focal mechanisms. This is attributed to the low stress and general dilative strain environment in which the fracturing occurs.

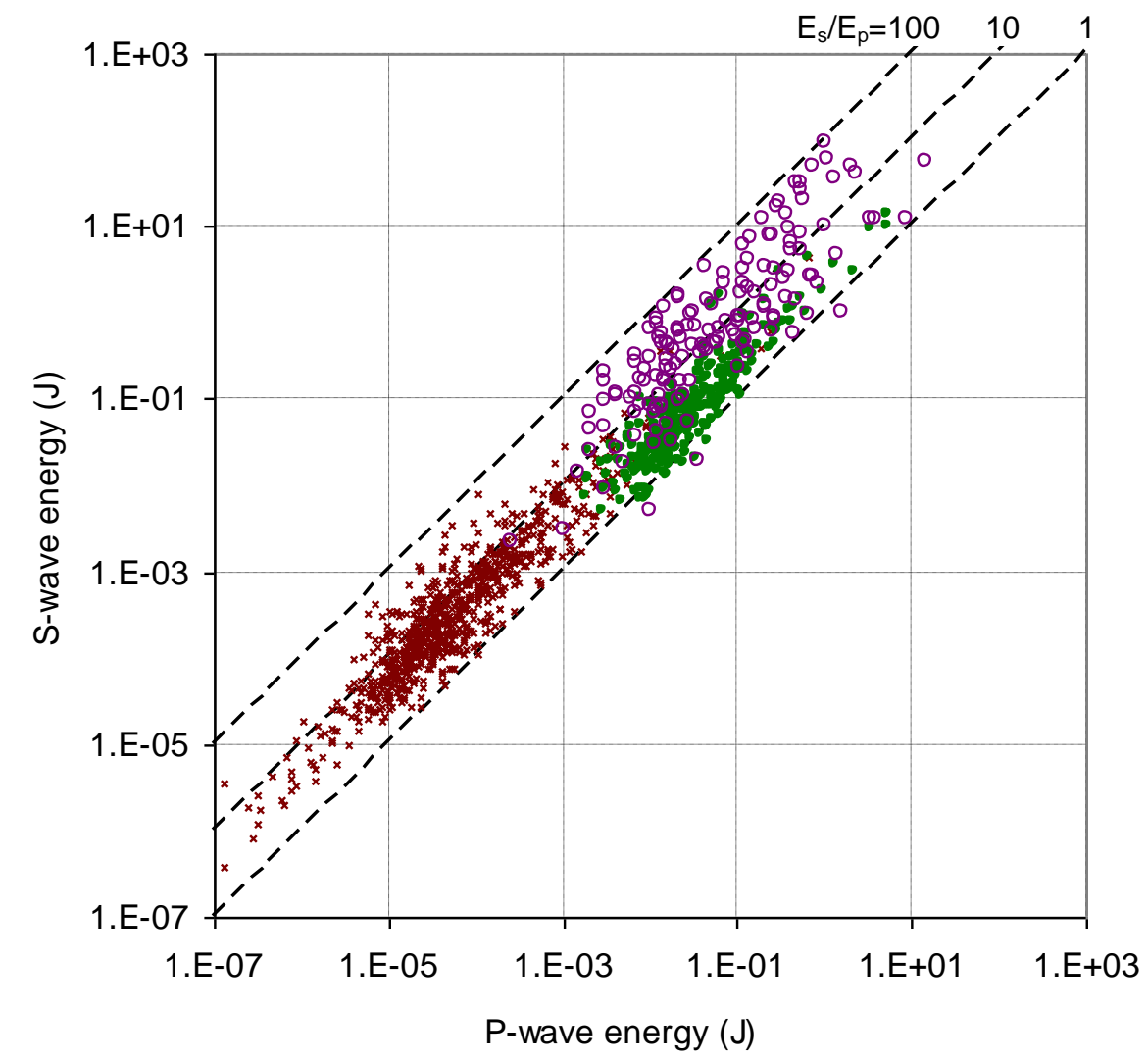

* URL Mine-by tunnel - Open pit Mine A $\quad$ URL shaft

Figure 6 S-wave versus P-wave energy comparison between data from URL and Mine A

Table 3 Comparison between distributions of S:P wave energy ratio

\begin{tabular}{cccccc}
\hline & Mine A & URL Mine-by & URL Shaft & $\begin{array}{c}\text { Underground } \\
\text { Mines General }\end{array}$ & Earthquakes** \\
\hline Range & $0.6-11$ & $1-20 *$ & $0.5-93$ & $1.5-30$ & $20-300$ \\
Mean & 2.1 & 6.37 & 21 & \\
10 percentile & 1.05 & 2.64 & 3 & \\
90 percentile & 5.04 & 15.78 & 55 & & \\
* Data away from the tunnel face **Boatwright and Fletcher (1984) & &
\end{tabular}

* Data away from the tunnel face ${ }^{* * B}$ Boatwright and Fletcher (1984) 


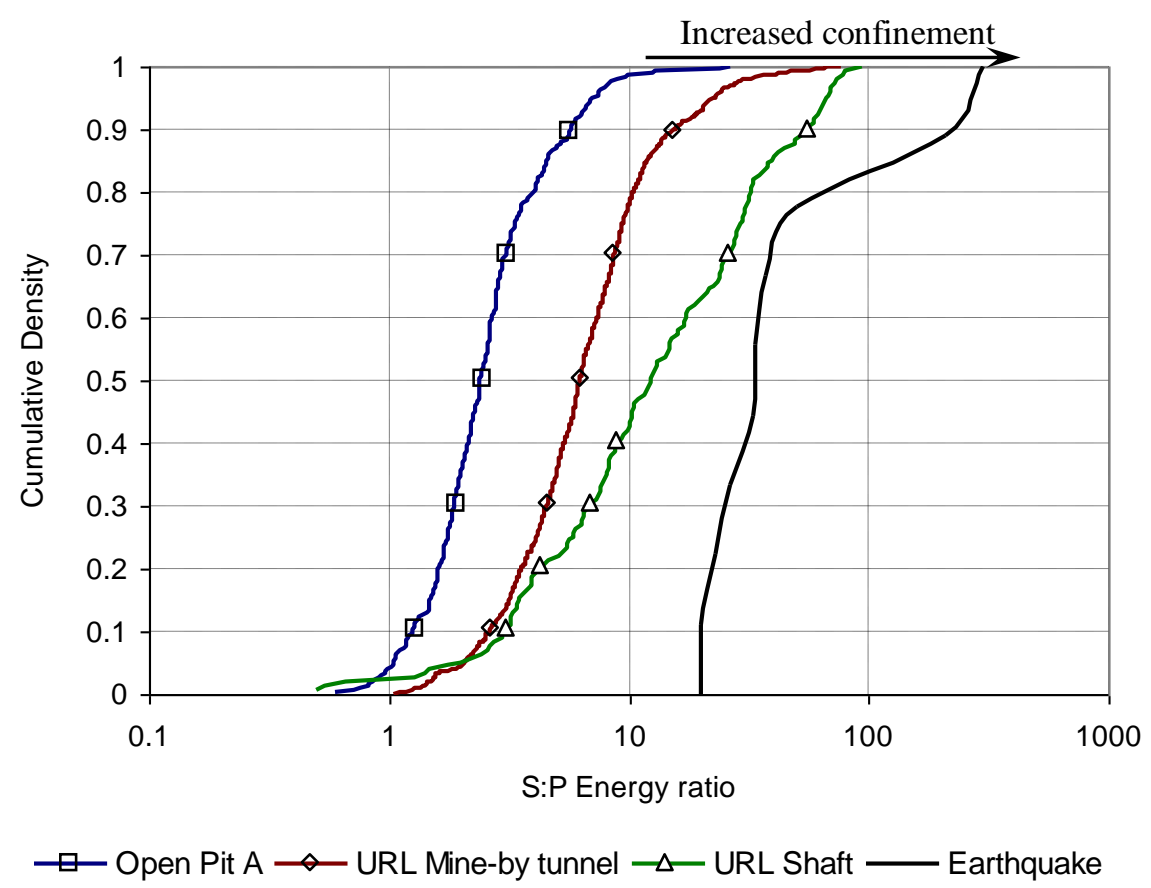

Figure 7 Distribution of S:P energy ratio from different environments

\section{Assessment of microseismicity at Mine A with respect to the general stress regime}

\subsection{Spatial and temporal distribution of seismicity at Mine A}

Seismic location is often regarded as the most important seismic source parameter as this influences the interpretation of the seismicity and the calculation of other source parameters. This is also true for microseismicity in open pit mines and emphasis needs to be placed on location of the seismic events for the early interpretation of localised movement on large structures or the localisation of rock mass damage accumulation.

At Mine A, there does not appear to be any distinct clustering of microseismicity around any of the known major structures or contacts. The spatial distribution of microseismicity at Mine A is shown in Figure 8. This measured seismicity is consistent with the concept of the primary brittle processes referred to in Section 1.

Although a study of the spatio-temporal distribution of the microseismicity is hampered by the frequent and sometime fairly long periods of system down time, there appears to be some spatio-temporal change in the seismicity over the monitored period.

Figure 9 shows a view of the monitored volume, looking north-west. The data is plotted for two periods, the first being a four month period from the start of the monitoring and the second an eight month period. It appears that the spatial distribution of the data at the start of data recording is randomly located around the seismic array. As mining progresses in the area to the north of the array, the centre of the seismogenic cluster moves to the north.

The northward movement of the seismogenic zone as mining progresses in the northern part of the pit indicates that the monitored seismicity is a result of the rock mass response to the changes in stress resulting from the mining activity. 


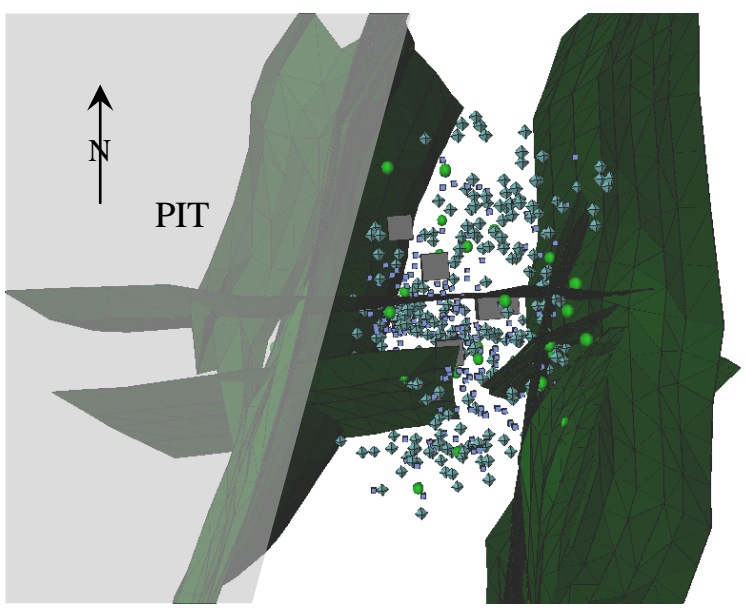

Figure 8 Spatial distribution of seismicity at Mine A

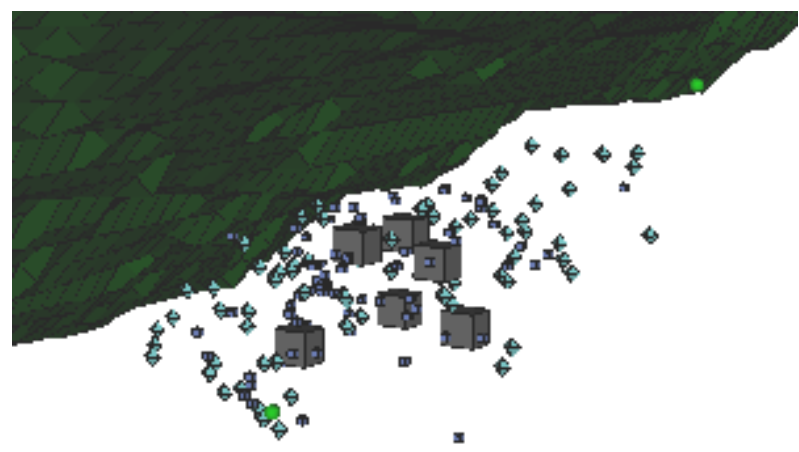

a) Stage 1

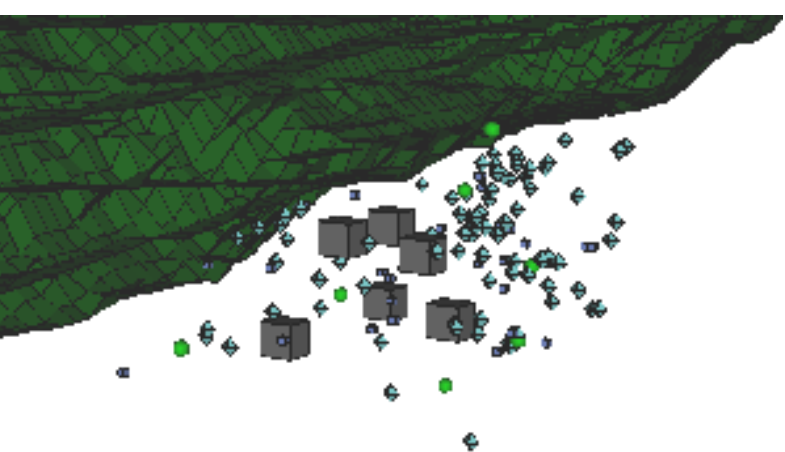

b) Stage 2

\section{Figure 9 Spatio-temporal distribution of seismicity at Mine A}

\subsection{Analysis of the stress state at the seismic source locations at Mine A}

Stress analysis was performed to facilitate a better understanding of the rock mass behaviour resulting in the recorded seismicity at Mine A. Although exhibiting a large variability, the rock mass is fairly competent, with intact rock strength of about $100 \mathrm{MPa}$ and expected values of 86 for the RQD and 73 for the RMR.

Linear elastic analyses were performed, as this idealisation is deemed acceptable as the microseismicity measured at the site is regarded as resulting from pre-peak stable fracture growth, which falls within the linear deformation range of the rock (Figure 10) (Martin, 1997).

The general stress change shown by the analyses is a reduction in all three of the principal stresses close to the slope. A larger stress change occurred to the northern side of the seismic array.

The stress state at each of the seismic locations at the date of its occurrence is shown in Figure 11. Figure 11 (a) shows a plot of the calculated $\sigma_{1}-\sigma_{3}$ relationship for the recorded seismic data. Also shown in the graph is an estimate of the intact strength and Hoek-Brown rock mass strength envelopes for "disturbed" $(\mathrm{D}=0)$ and "undisturbed" $(\mathrm{D}=1)$ rock masses. 


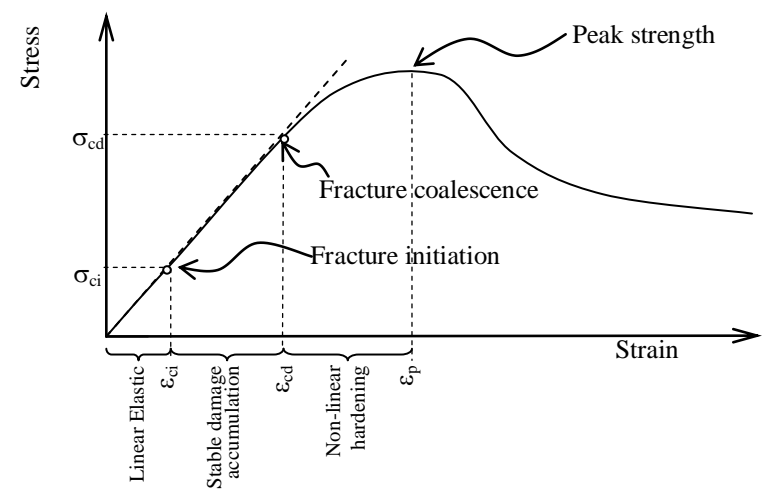

Figure 10 Schematic representation of stress-strain response of rock mass
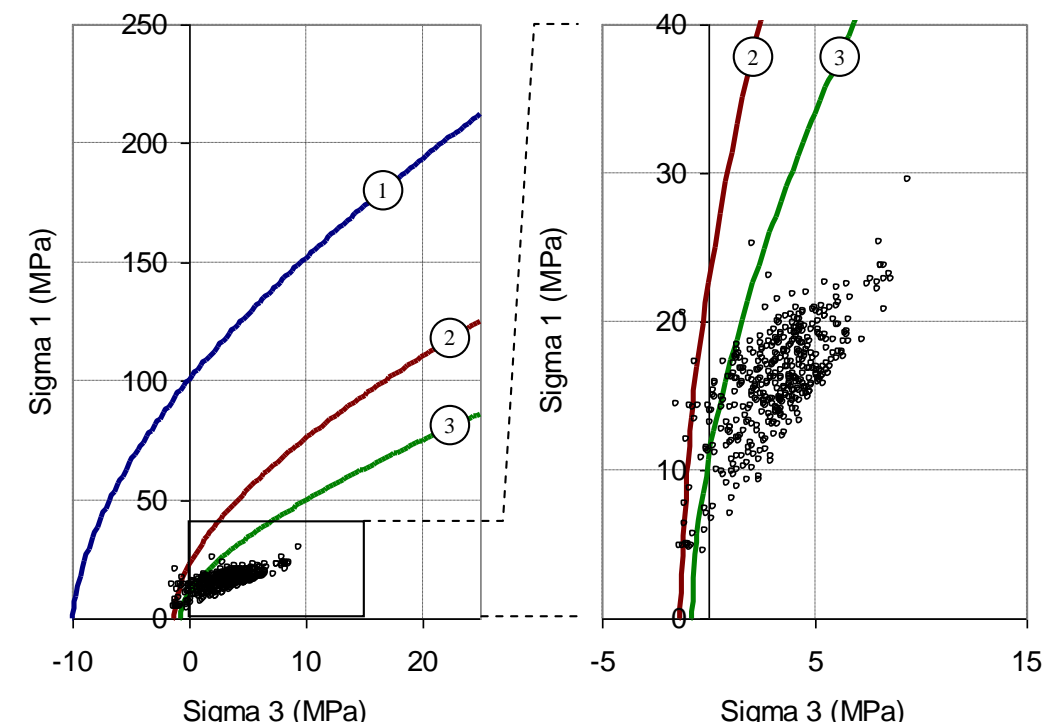

a)

b)

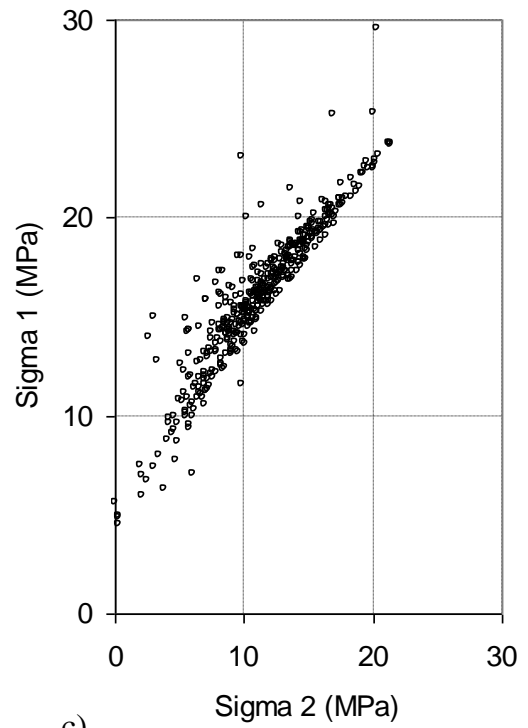

c)

- (1)- Intact Rock Mass ( $(D=0)$

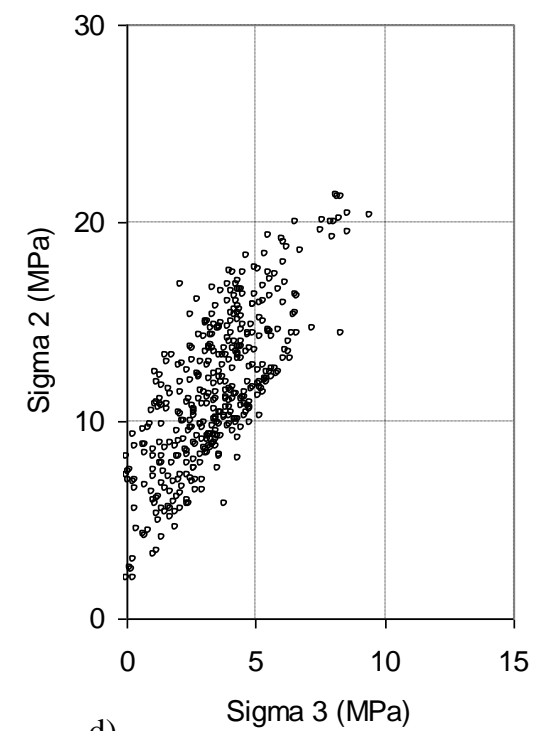

d)

-3) Rock Mass (D=1) - Mine A

Figure 11 Estimated stress state at occurrence of seismic event 


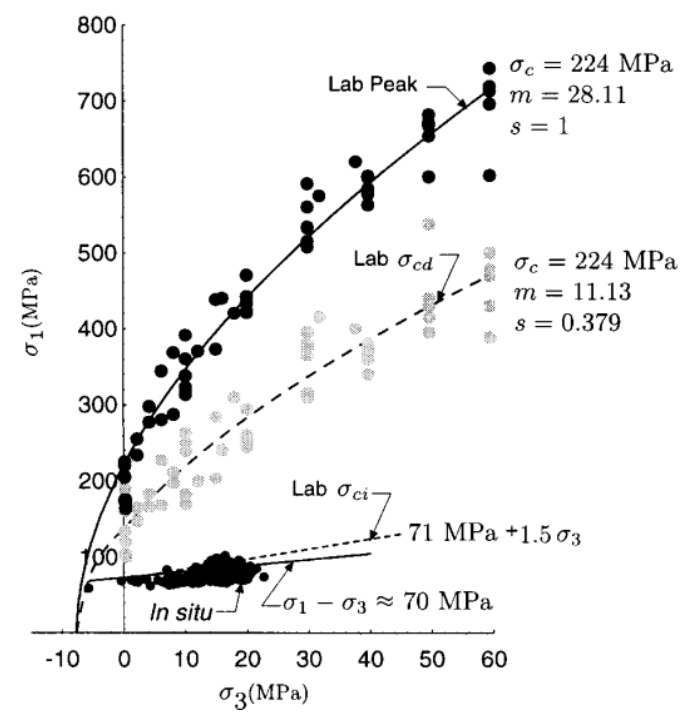

Figure 12 Stresses at fracturing estimated from microseismic monitoring at the mine by tunnel URL Canada (Martin, 1997)

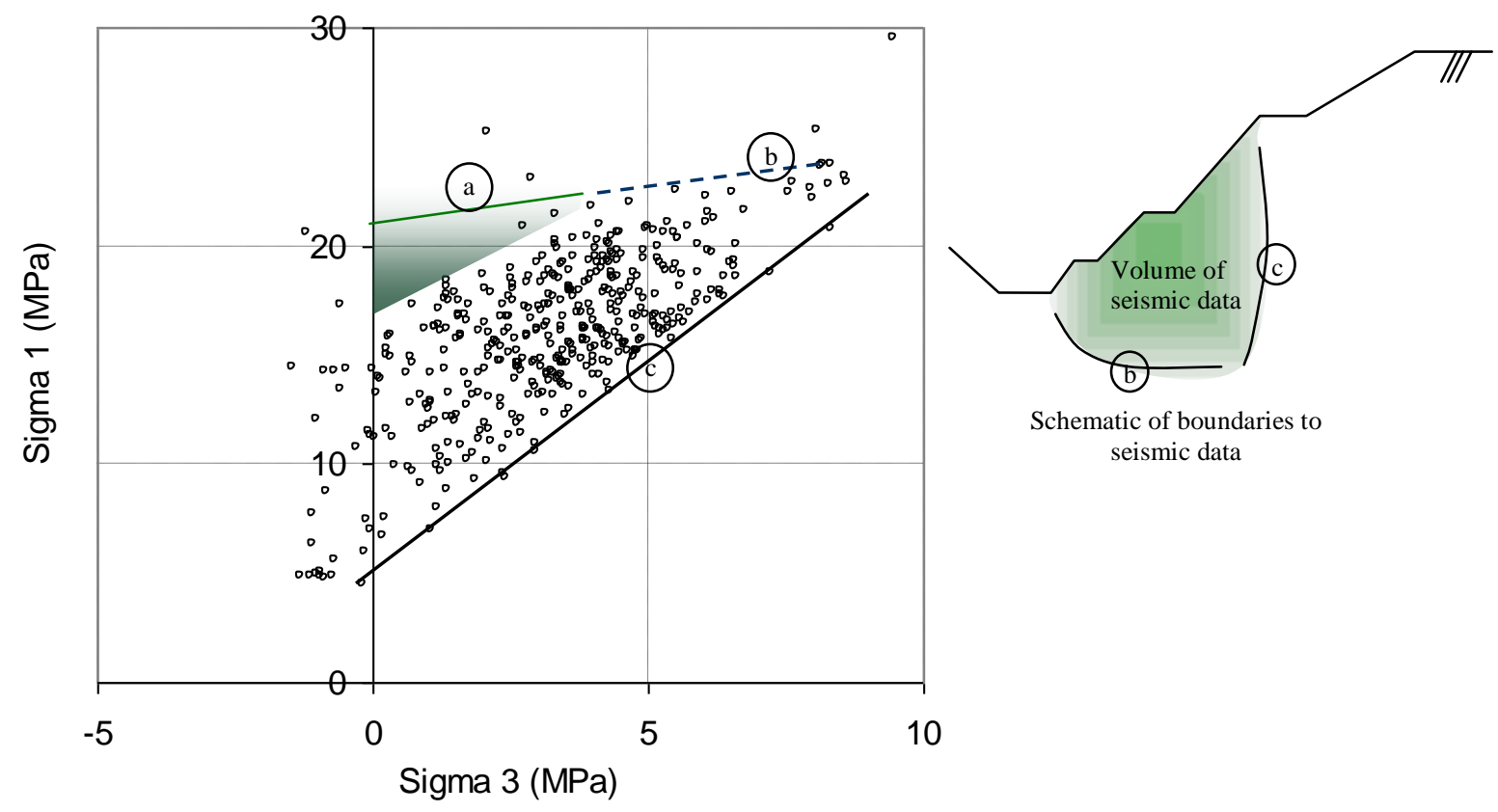

Figure 13 Estimated stress state at occurrence of seismic event

Fracturing in the slope occurs at stress levels below the estimated Hoek-Brown rock mass strength. The relationship between the estimated stress at fracturing and the Hoek-Brown strength estimate is similar to the experience from underground tunnelling presented by Martin (1997) and shown in Figure 12.

The calculated $\sigma_{1}-\sigma_{3}$ stress state at the source location at the time of the event is repeated in Figure 13, with three boundary lines drawn on it. The area bounded by these lines represents the possible stress state within the volume defined by the measured seismicity. The shaded area below boundary $a$ represents an area lacking data where seismicity would be expected. The stress state represented by the shaded area occurs close to the slope face. The lack of data in this area is attributed to poor location of these near surface events. The boundary $b$ corresponds to the boundary of measured seismicity below the seismic array and may partly be due to the lack in sensitivity of the seismic array in these areas. Boundary $c$ is well defined and represents the boundary of the measured seismic locations furthest away from the slope along the strike 
to the slope face. Although this appears to be a true seismogenic boundary, this may also have been influence by a lithological contact in the vicinity of boundary $c$. Due to relaxation of the normal stress, this contact may have opened enough to cause stronger attenuation of events to the east of the contact. However, considering the general stress state, boundary $c$, appears to be the true seismogenic boundary. This will be discussed later in this section.

The crack initiation stress, also referred to as the threshold for damage for intact rock, has been defined by Hommand-Etienne et al. (1995) for Lac du Bonnet granite as:

$$
\sigma_{\mathrm{ci}} \approx \mathrm{A}_{\mathrm{i}} \cdot \mathrm{UCS}+\mathrm{B}_{\mathrm{i}} \cdot \sigma_{3}
$$

The value of $A_{i}$ for intact rock appears to be about $0.25-0.3$ while the value $B_{i}$ may vary between about 1 and 2 (cf. Stacey, 1981; Hommand-Etienne et al., 1995; Brace et al., 1966; Pestman and van Munster, 1996).

In a similar vein, the damage initiation stress for rock masses can be defined as:

$$
\sigma_{\mathrm{cim}} \approx \mathrm{A}_{\mathrm{im}} \cdot \mathrm{UCS}+\mathrm{B}_{\mathrm{im}} \cdot \sigma_{3}
$$

The value of $A_{\text {im }}$ for the monitored rock mass at Mine A is about 0.1 , which is about $0.3-0.4$ of the value of $A_{i}$. Such low values for $A_{i m}$ have been reported by several authors (cf. Stacey and Yathavan, 2003) and may be attributed to the pre-existing joints and fractures creating localised stress concentration and promotion of fracture growth at seemingly lower stresses than for intact rock.

As mentioned before, the value of $B_{\text {im }}$ generally appears to vary between 1 and 2 . As a result of an incomplete data set, the value of $B_{i m}$ can not be obtained directly by best-fit procedures. Considering the general stress state, however, a $B_{\text {im }}$ value of 1.9 appears to be the most reasonable assumption. Figure 14 plots contours of increased damage assuming $B_{i m}$ values of 1,1.4 and 1.9. The contoured zone in the figures represents the rock mass which is expected to accumulate damage due to the stress change in the rock mass. From these plots it appears that the higher $B_{i m}$ value results in a more realistic prediction of the damage zone. As seismic activity outside of boundary $c$ will favour a lower value of $B_{i m}$, this also supports the assumption that boundary $c$ is the seismogenic boundary.

The empirical relation shown in Equation (Error! Not a valid link.) is often interpreted in terms of the well known Mohr-Coulomb strength criteria, where $A_{i m}$ and $B_{i m}$ are defined as:

$$
\mathrm{A}_{\mathrm{im}}=\frac{2 \cdot \mathrm{c} \cdot \cos (\phi)}{1+\sin (\phi)} \quad \text { and } \quad \mathrm{B}_{\mathrm{im}}=\frac{1-\sin (\phi)}{1+\sin (\phi)}
$$

Interpreting the data with the Mohr-Coulomb model indicates for a $B_{i m}$ of 2 an angle of friction of $20^{\circ}$ with a cohesion of about $7 \mathrm{MPa}$. As friction can not be mobilised before the cohesion is broken down, the stress threshold for damage is expected to be representative of the frictionless state. The concepts developed by Martin and co-workers argues that the frictional strength of rocks is only mobilised at large strains, while the cohesive strength determines the strength at small strains (Martin, 1993; Hajiabdolmajid et al., 2003).

Diederichs (2003) points out that this confinement dependency is not the result of conventional sliding friction, but rather of the elastic generation of extension strain and tensile crack accumulation in which friction plays no part. This apparent friction angle can be explained by the extension strain criterion first proposed by Stacey (1981). This is shown in Figure 14(c), where the fracture initiation envelope assuming the extension strain criterion is plotted on the graph as a dashed line.

The measured behaviour of the rock mass at Mine A is consistent with the rock mass damage processes expected to occur in the primary phase of brittle fracture in slopes and corresponds to the initial high cohesion, low friction state of the cohesion-hardening-friction-softening model presented by Hajiabdolmajid and co-workers (Hajiabdolmajid et al., 2002; 2003; Hajiabdolmajid and Kaiser, 2002; 2003). 

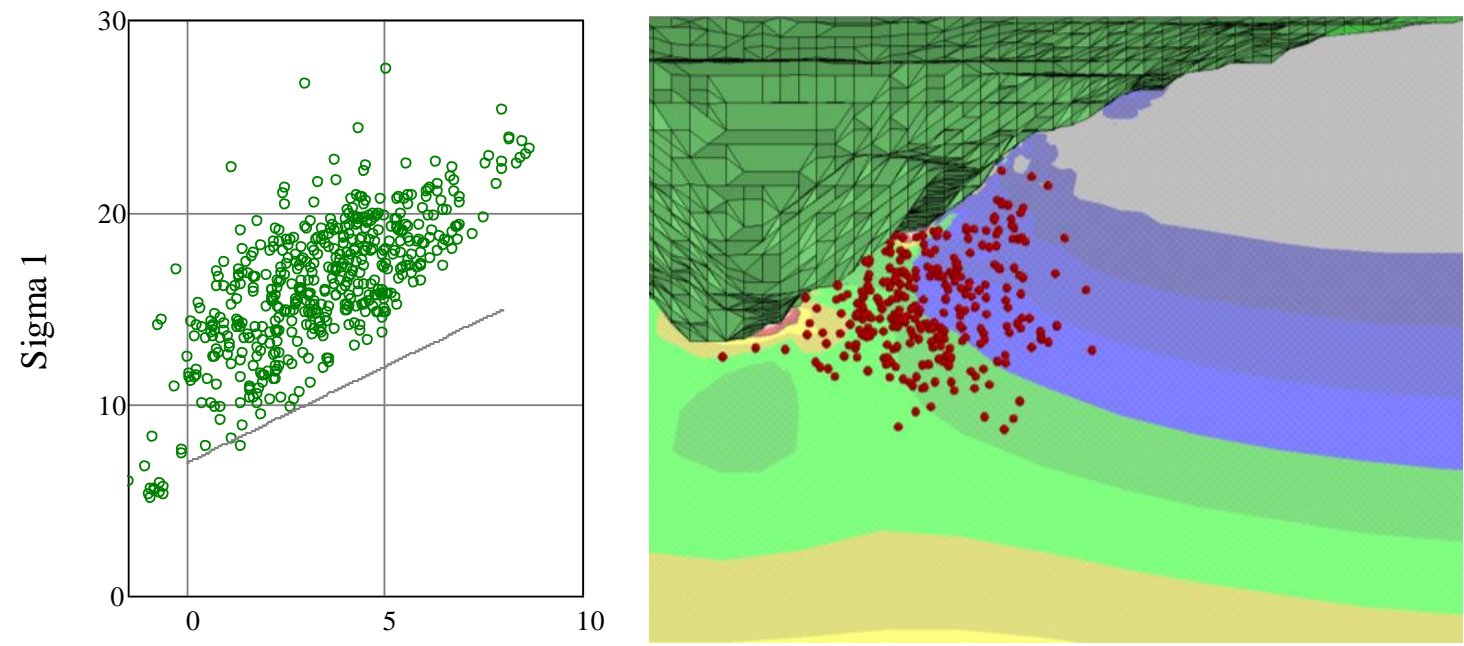

Sigma 3

a) $B_{\text {im }}=1$
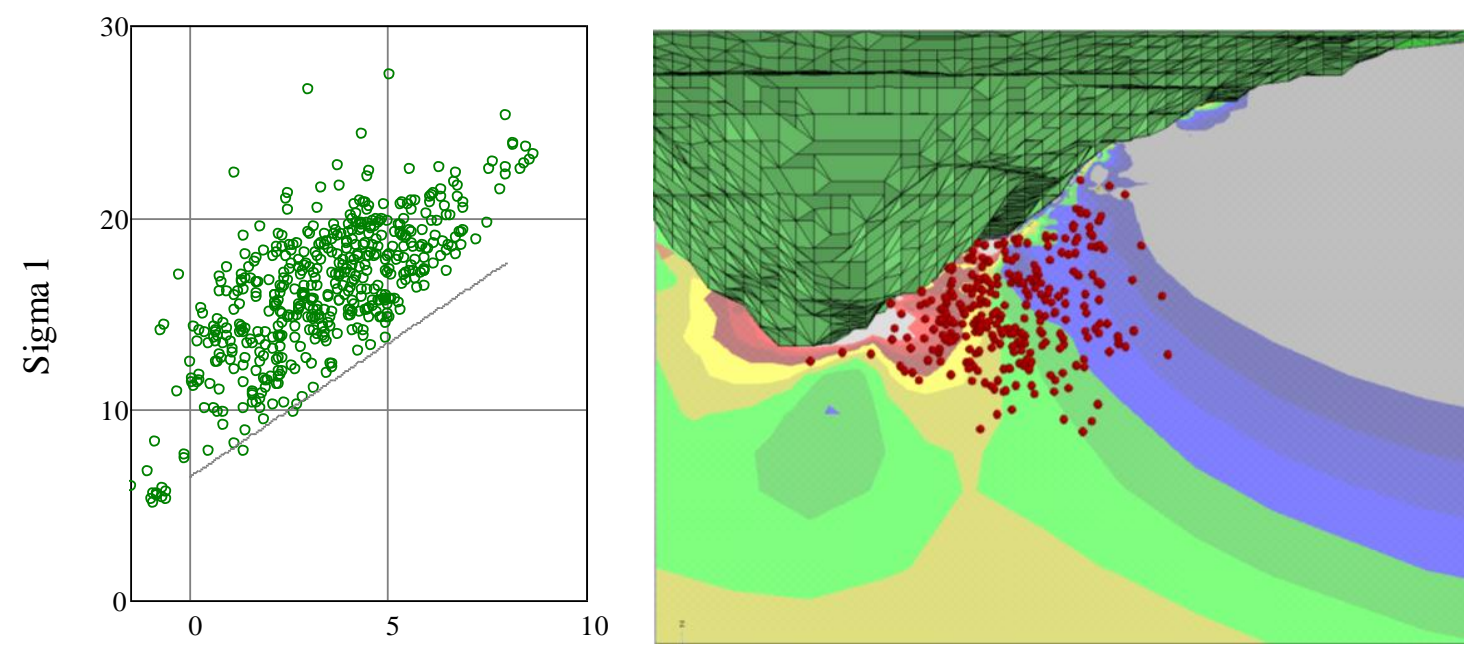

Sigma 3

b) $B_{\text {im }}=1.4$
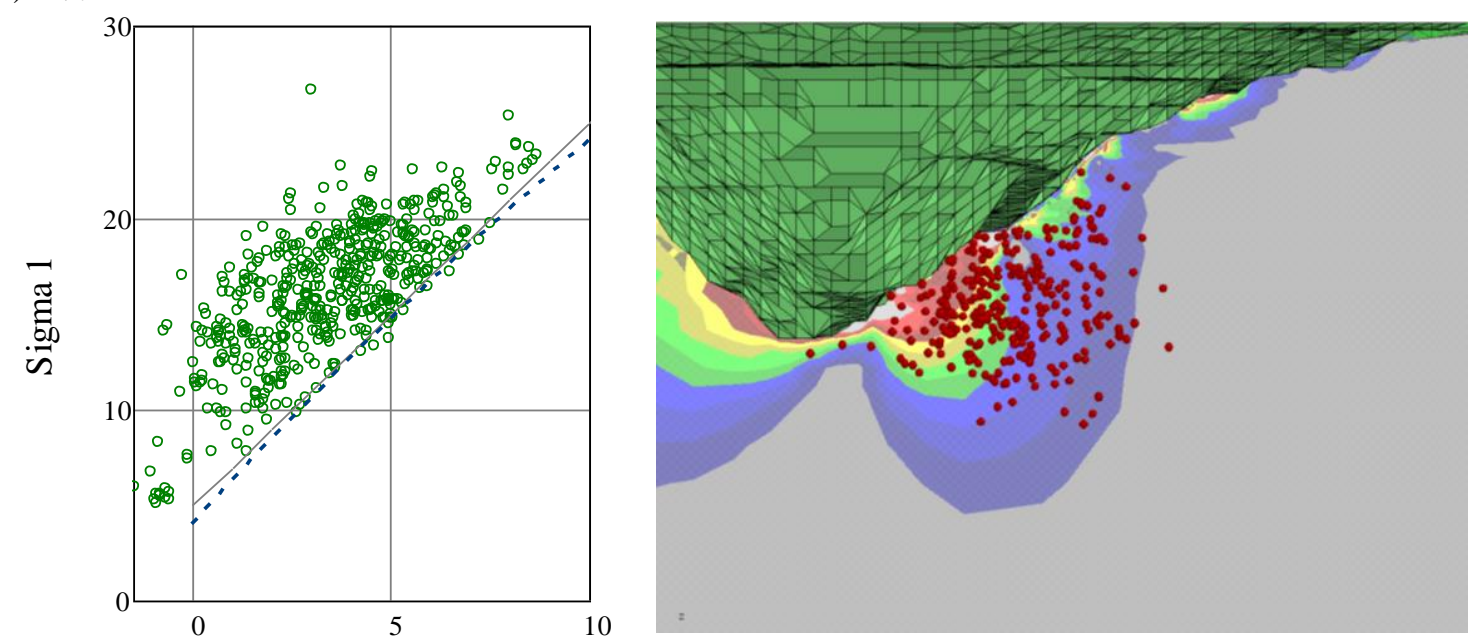

Sigma 3

c) $B_{\text {im }}=1.9$

Figure 14 Assumed boundary $c$ with $B_{i m}=1,1.4$ and 1.9 and corresponding expected seismogenic zone 


\section{Conclusion}

Open pit mine slopes are likely to increase in depth in the future. With this comes an increased stress environment and a greater uncertainty regarding the mechanical behaviour of the slopes. Microseismicity detectable in the slope provides a valuable source of information about its mechanical behaviour.

Microseismic monitoring has been used at several large natural rock slopes, civil and open pit mine slopes with varying degrees of success. From the literature it appears that the technology in the monitoring of natural and cut slopes for civil excavations is not regarded as having reach maturity, in the sense that it can be used as a routine monitoring method. The studies are often preliminary or experimental in nature and require a great deal of expert interpretation.

From the experience gained from civil excavations and large natural slopes it appears that microseismic monitoring can provide valuable insight into all three of the brittle fracture processes described by Stead et al. (2007).

Due to the low stress environment, the seismicity associated with the fracturing within a slope is weak, and as a result, difficult to process and separate from noise. Current seismic systems are rigid compared to the dynamically changing mining environment. Further hardware and software development, for noise filtering and automatic processing, needs to be done.

The interpretation of seismic source parameters for seismic events in the open pit environment is unclear and further research in this area should be done.

The seismicity experienced at Mine A exhibited a low S-wave to P-wave energy ratio and high $b$-value for the frequency-magnitude relationship, which is consistent with the concepts of extensional fracture damage accumulation in the slope.

Fracture initiation at Mine A occurs at equivalent uniaxial stress levels of about $10 \%$ of the intact UCS, which is below the expected rock mass strength. The monitored rock mass response at Mine A appears to be consistent with both the conceptual model for the development of instability in hard rock slopes suggested by Eberhardt et al. (2004) and Stead et al. (2007), as well as the concepts underlying the cohesion-softeningfriction-hardening constitutive models.

\section{Acknowledgements}

This study was funded as part of the project High Resolution Seismic Monitoring in Open Pit Mines carried out under the auspices of the Australian Centre for Geomechanics. Financial support for this project was provided by Minerals and Energy Research Institute of Western Australia, BHP Billiton Nickel West and Xstrata Zinc (Black Star Pit - Mt Isa).

\section{References}

Amitrano, D., Grasso, J.R. and Senfaute, G. (2005) Seismic precursory patterns before a cliff collapse and critical point phenomena, Geophysical Research Letters, Vol. 32, 108314, pp. 1-5.

Boatwright, J. and Fletcher, J.B. (1984) The partition of radiated energy between P and S waves, Vol. 74 (2), pp. 361-375.

Brückl, E. and Mertl, S. (2006) Seismic monitoring of deep-seated mass movements, Proceedings Interpraevent International Symposium Disaster Mitigation of Debris Flows, Slope Failures and Landslides held on September 25-27, 2006, Niigata, Japan.

Brückl, E. and Mertl, S. (2007) Observation of fracture processes in creeping rock masses by seismic monitoring, 11th Congress of the International Society for Rock Mechanics, Lisbon Portugal, 9-13 July 2007.

Cai, M., Kaiser, P.K. and Martin, C.D. (1998) A Tensile Model for the Interpretation of Microseismic Events near Underground Openings, Pure and Applied Geophysics, Vol. 153(1), pp. 67-92.

Chen, Z., Stewart, R., Bland, H. and Thurston, J. (2004) Spacial distribution of microseisms at Turtle Mountain, CREWES Research Report, Vol. 16, pp. 1-18.

Clement, C., Merrien-Soukatchoff, V., Gueniffey, Y. and Dünner, C. (2006) Correlation between climatic variation and microseismic events collected on a large fractured slope: application of statistical techniques, Geophysical Research Abstracts, Vol. 8, 01599.

Cowley, D. (1998) Paringa Seismic Trial, KCGM internal report, unpublished. 
Deza, E. and Jaén, H. (1979) Microtemblores de ultrafrecuencia con la explotacion minera a tajo abierto en Cerro de Pasco, Bol. Soc. Geol. Peru, Vol. 63, pp. 237-247.

Diederichs, M.S. (2003) Manuel Rocha Medal Recipient: Rock Fracture and Collapse Under Low Confinement Conditions, Rock Mechanics and Rock Engineering, Vol. 36(5), pp. 339-381.

Eberhardt, E., Spillmann, T., Maurer, H., Willenberg, H., Loew, S. and Stead, D. (2004) The Randa Rockslide Laboratory: establishing brittle and ductile instability mechanisms using numerical modelling and microseismicity, Landslides: Evaluation and Stabilization, Lacerda, Ehrlich, Fontoura and Sayao (editors), Taylor and Francis Group, London, pp. 481-487.

Einstein, H.H., Veneziano, D., Baecher, G.B. and O'Reilly, K.J. (1983) The effect of discontinuity persistence on rock slope stability, International Journal of Rock Mechanics and Mining Sciences and Geomechanics Abstracts, Vol. 20 No. 5, pp. 227-236.

Gibowicz, S.J., Young, R.P., Talebi, S. and Rawlence, D.J. (1991) Source parameters of seismic event at the underground research laboratory in Manitoba Canada: Scaling Relations for events with moment magnitude smaller than -2, Bulletin of the seismological Society of America, 81 (4), pp. 1157-1182.

Gibowicz, S.J and Kijko, A. (1994) An Introduction to Mine Seismology, Academic Press, New York, 399 p.

Hajiabdolmajid, V., Kaiser, P.K. and Martin, C.D. (2002) Modelling brittle failure of rock, International Journal of Rock Mechanics and Mining Sciences, 39, pp. 731-741.

Hajiabdolmajid, V., Kaiser, P.K. and Martin, C.D. (2003) Mobilised strength components in brittle failure of rock, Géotechnique 53, No. 3, pp. 327-336.

Hajiabdolmajid, V. and Kaiser, P.K. (2002) Modelling Slopes in Brittle Rock, in NARMS-TAC 2002: Mining and Tunnelling Innovation and Opportunity, R. Reginald Hammah, Will Bawden, John Curran, Mark Telesnicki (editors) Toronto, University of Toronto Press. Vol. 1, pp. 331-338.

Hajiabdolmajid, V. and Kaiser, P. (2003) Brittleness of rock and stability assessment in hard rock tunneling, Tunnelling and Underground Space Technology, 18, pp. 35-48.

Hardy, H.R. (1981) Application of acoustic emission techniques to rock and rock structures: A state-of-the-art review. Acoustic Emissions in Geotechnical Engineering Practice, STP 750. V.P. Drnovich and R.E. Gray (editors), American Society for Testing of Materials, pp. 4-92.

Hardy, H.R (1994) Geotechnical field applications of AE/M S techniques at the Pennsylvania State University: a historical review, NDT and E International, Vol. 27, No. 4, pp. 191-200.

Hardy, H.R. and Kimble, E.J. (1991) Application of high-frequency AE/MS techniques to rock slope monitoring, in Proceedings Fifth Conference on AE/MS Activity in Geologic Structures and Materials, H.R. Hardy (editor), Trans Tech, Clausthal-Zellerfeld, Germany, pp. 457-477.

Hommand, F., Hoxha, D., Shao, J.F., Sibai, M. and Duveau, G. (1995) Endommagement de granites et de marnes: Essais mechaniques, identification des parameters d'un modele d'endommagement et simulation, Final Report B RP O.ENG/O.LML 95.015. ENGS Laboratoire de Géomécanique, Nancy.

Hudyma, M.R., Milne, D. and Grant, D.R. (1995) Geomechanics of Sill Pillar Mining in Rockburst Prone Conditions. Phase 1 Report: sill pillar monitoring using conventional methods, Report prepared for the Mining Research Directorate, $104 \mathrm{p}$.

Hudyma, M., Jiang, J. and Reimnitz, M. (2003), Seismic Monitoring at the Fimiston Open Pit Kalgoorlie Consolidated Gold Mines (KCGM), Proceedings Fifth Large Open Pit Conference, C.L. Workman-Davies and E. Chanda (editors), pp. 235-246.

Ishida, T., Nishikawa, T., Tanaka, M. and Shiotani, T. (2001) Acoustic emission monitoring for and unstable rock mass left after slope failure, Rockburst and Seismicity in Mines - RaSiM5, South African Institute of Mining and Metallurgy, pp. 29-33.

Jennings, J.E. and Steffen, O.K.H. (1967) The Analysis of the stability of slopes in deep opencast mines, The Civil Engineer in South Africa.

Kable, S.R. (2005) A review of the microseismic monitoring at the Fimiston open pit mine, Undergraduate thesis, Bachelor of Engineering, Curtin University of Technology, Kalgoorlie, Australia.

Koerner, R.M., McCabe, W.M. and Lord, A.E. (1981) Overview of acoustic emission monitoring of rock structures, Rock Mechanics, 14, pp. 27-35.

Lajtai, E.Z. (1969) Strength of discontinuous rocks in shear, Geotechnique, Vol. 19, No. 2, pp. 218-233.

Legge, N.B. and Spottiswoode, S.M. (1987) Fracturing and microseismicity ahead of a deep gold mine stope in the preremnant stages of mining, Proceeding 6th Int. Congress on Rock Mech., Montreal, September 1987, pp. 1071-1078.

Lynch, R.A., Wuite, R., Smith, B.S. and Cichowicz, A. (2005) Microseismic monitoring of open pit slopes, Proceedings 6th International Symposium on Rockburst and Seismicity in Mines, Y. Potvin and M. Hudyma (editors), Australian Centre for Geomechanics, 9-11 March 2005, pp. 581-592.

Lynch, R.A. and Malovichko, D.A. (2006) Seismology and slope stability in open pit mines, International Symposium on Stability of Rock Slopes in Open Pit Mining and Civil Engineering, pp. 375-389. 
Martin, C. (1997) Seventeenth Canadian Geotechnical Colloquium: The effect of cohesion loss and stress path on brittle rock strength, Canadian Geotechnical Journal, Vol. 34(5), pp. 698-725.

Martin, C.D. (1993) The Strength of Massive Lac Du Bonnet Granite around Underground Openings, Phd Thesis, University of Manitoba.

McCauley, M.L. (1976) Microsonic detection of landslides, 54th T.R.B annual meeting, Transportation Research Record 581, Washington DC, pp. 25-30.

Napier, J.A.L., Dresher, K., Hildyard, M.W., Kataka, M.O., Malan, D.F. and Sellers, E.J. (2002) Experimental investigation of fundamental processes in mining induced fracturing and rock instability, Final SIMRAC project, report (GAP601b).

Pestman, B.J. and van Munster, J.G. (1996) An Acoustic Emission Study of Damage Development and Stress-Memory Effects in Sandstone, International Journal of Rock Mechanics and Mining Sciences and Geomechanics Abstracts, Vol. 33, No. 6, pp. 585-59.

Roth, M. and Blikra, L.H. (2007) Seismic monitoring of the unstable Asknes rock slope, Norway, Geophysical Research Abstracts, Vol. 9, 06198.

Sato, T. (1978) A not on Body-wave Radiation from Expanding Tension Crack, Scientific report Tohoku University, Ser. 5, Geophysics. 25, pp. 1-10.

Stead, D., Coggan, J.S. Elmo, D. and Yan, M. (2007) Modelling brittle fracture in rock slopes - experienced gain and lessons learned, Slope Stability 2007 - Proceedings International Symposium on Rock Slope Stability in Open Pit Mining and Civil Engineering, Y. Potvin (editor), Australian Centre for Geomechanics, 12-14 September 2007, Perth, Australia. pp. 239-251.

Stacey, T.R. (1981) A simple extension strain criterion for fracture of brittle rock, International Journal of Rock Mechanics and Mining Sciences, Vol. 18, pp. 469-474.

Stacey, T.R., Xianbin, Y., Armstrong, R. and Keyter, G.J. (2003) New slope stability considerations for deep open pit mines. Journal of the South African Institute of Mining and Metallurgy, Vol. 103, No. 6, pp. 373-389.

Stacey, T.R. and Yathavan, K. (2003) Examples of Fracturing of Rock at Very Low Stress Levels, ISRM 2003 Technology Roadmap for Rock Mechanics, S. Afr. Inst. Min. Metall., pp. 1155-1159.

Stacey, T.R. (2007) Slope stability in high stress and hard rock conditions, Slope Stability 2007 - Proceedings International Symposium on Rock Slope Stability in Open Pit Mining and Civil Engineering, Potvin (editor), Australian Centre for Geomechanics, 12-14 September 2007, Perth, Australia. pp. 187-200.

Stewart, R., Bland, H., Thurston, J. and Hall, K. (2004) The surface microseismic monitoring system on Turtle Mountain, Alberta, Focus Article, CSEG RECORDER, November 2004. http://www.cseg.ca/publications/recorder/2004/11 nov/nov04-turtle-mountain.pdf.

Sweby, G.J., Trifu, C-I., Goodchild, D.J. and Morris, L.D. (2006) High-resolution seismic monitoring at Mt. Keith open pit mine. Golden Rocks 2006, The 41st U.S. Symposium on Rock Mechanics (USRMS), Golden, Colorado, June 17-21, 2006.

Trifu, C-I., Shumila, V. and Leslie, I. (2008) Application of joint seismic event location techniques at Chuquicamata open pit mine, Chile, Proceedings 5th International Conference and Exhibition on Mass Mining, Luleå, Sweden, 9-11 June, 2008, pp. 943-952.

Willenberg, H., Spillmann, T., Eberhardt, E., Evans, K., Loew, S. and Maurer, H.R. (2002) Multidisciplinary monitoring of progressive failure processes in brittle rock slopes - concepts and system design, 1st European Conference on Landslides, 24-26 June, 2002, Prague, Czech Republic. pp. 477-483. 